\title{
Konjenital koksa vara
}

\author{
Congenital coxa vara
}

\author{
Oktay Adanır, Ozan Beytemür, Akif Güleç
}

Bağcılar Eğitim ve Araştırma Hastanesi, Ortopedi ve Travmatoloji Kliniği, İstanbul

\begin{abstract}
Gelişimsel koksa vara (GKV) kollodiyafizer açının azalması, femur boynunun kısalması, büyük trokanterin göreceli olarak aşırı büyümesi ve etkilenen ekstremitenin kısalığı ile karakterize, nadir görülen ve nedeni tam olarak bilinmeyen gelişimsel bir bozukluktur. Tek taraflı olgularda ağrısız aksama, çift taraflı olgularda ise ördekvari yürüyüş ve artmış lomber lordoz bulguları vardır. Pelvis önarka grafisinde kollodiyafizer açı azalmıştır, proksimal fiz vertikal yerleşimlidir. Tüm olgularda görülmese de femur boynunun mediyalindeki üçgen şeklindeki kemik parçası gelişimsel koksa vara olgularına karakteristik radyolojik bulgudur. GKV tedavisindeki amaç femur boynundaki defektin iyileşmesini sağlamak, bacak boy eşitsizliğini düzeltmek, kollodiyafizer açıyı normal değerlere getirmek ve kalça biyomekaniğini düzelterek kalça abduktorlarının normal fonksiyon görmesini sağlamaktır. Abduksiyon cihazları ve traksiyon gibi konservatif yöntemlerin tedavide yeri yoktur. Tek etkili tedavi intertrokanterik ya da subtrokanterik seviyeden yapılacak olan valgus osteotomisidir. Cerrahi tedavi kararı $\mathrm{H}-\mathrm{E}$ açı değerine ve semptomlara göre alınır. Cerrahi tedavi sonrası deformitenin tekrarlamaması için $\mathrm{H}-\mathrm{E}$ açısının $38-40^{\circ}$ 'nin altına indirilmesi gerekmektedir.
\end{abstract}

Anahtar sözcükler: coxa vara, gelişimsel; osteotomi, valgus
Devolopmental coxa vara is a rare devolopmental abnormality with an unknown etiology; characterized by an abnormal decrease in the femur neck-shaft angle, shortening of the femoral neck, relative overgrowth of the greater trochanter and shortening of the affected lower limb. Unilateral cases present with painless limp and bilateral cases present with a waddling gait and increased lumbar lordosis. Plain antero-posterior pelvis radiographs demonstrate decreased neck-shaft angle and vertikal orientation of the proximal femoral physis. Triangular piece of bone in the medial femoral neck is a characteristic radiological finding of devolopmental coxa vara but not seen in all cases. The purpose of treatment is to provide healing of the defective femoral neck, restore the limb length and neck-shaft angle to normal values, and also restore normal hip biomechanics for hip abductors to function normally. Conservative methods like abduction splinting and traction has no role in the treatment of this disorder. The only effective treatment is a valgus producing osteotomy done either at the intertrochanteric or subtrochanteric level. Indications for surgical treatment are the degree of $\mathrm{H}-\mathrm{E}$ angle and presence of symptoms. In order to prevent recurrence after surgical treatment, $\mathrm{H}-\mathrm{E}$ angle must be reduced below $38-40^{\circ}$.

Key words: coxa vara, devolopmental; osteotomy, valgus oksa vara; femur boyun-diyafiz açısının kabul edilen normal değerlerin altına inmesidir. Bilindiği üzere yeni doğan bir bebekte kollodiyafizer açı $150^{\circ}$ iken yıllar içerisinde azalarak yaşlı popülasyonda $120^{\circ}$ 'lere kadar inmektedir. Literatürde, konjenital koksa vara terminolojisi ve sınıflandırmasında kavram karmaşası vardır. "Konjenital", "gelişimsel", "servikal" ve "infantil" koksa vara terimleri aynı patolojiyi tanımlamak için kullanılmaktadır. Bu gelişimsel bozukluğu tanımlarken, bazı yazarlar konjenital kısa femur, proksimal fokal femoral yetmezlik gibi patolojilere bağlı gelişen koksa vara olgularını, bazıları ise iskelet displazilerine bağlı koksa vara olgularını konjenital ya da gelişimsel koksa vara olguları içine dahil etmişlerdir. ${ }^{[1]}$ Çocukluk çağında görülen koksa vara olguları, kabaca, konjenital kısa femur, proksimal fokal femoral yetmezliğe bağıı koksa vara; travma, enfeksiyon gibi nedenlere ikincil gelişen koksa vara; ve son olarak, gelişimsel koksa vara olarak üç grupta toplanabilir (Tablo 1). ${ }^{[2]}$

- İletişim adresi: Uzm. Dr. Oktay Adanır, T. C. Sağıı Bakanlı̆̆ı Bağcılar Eğitim ve Araştırma Hastanesi, Ortopedi ve Travmatoloji Kliniği, Bağcılar, İstanbul Tel: 0212 - 4404000 (1717) e-posta: droktayadanir@yahoo.com

- Geliş tarihi: 3 Eylül $2014 \quad$ Kabul tarihi: 3 Eylül 2014 
Tablo 1. Koksa vara sınıflaması

1) Konjenital kısa femur ve proksimal fokal femoral yetmezliğe bağlı koksa vara

2) Edinsel koksa vara

a) Travma:

- Femur boyun kırığı

- Travmatik kalça çıkı̆̆ı

b) Enfeksiyon:

- Femur başının septik nekrozu

- Proksimal femur osteomiyeliti

c) Femur başı epifiz kayması

d) Legg-Calvé-Perthes hastalığı

e) Osteogenesis imperfekta

f) Fibröz displazi

g) Raşitizm

h) Tümörler

i) İskelet displazileri:

- Kleidokraniyal dizostoz

- Metafizyel dizostoz

- Spondilometafizyel displazi

3) Gelişimsel koksa vara çocukta ağrısız bir aksama vardır. Aksamanın nedeni tek taraflı olgularda abduktor kasların fonksiyonel yetmezliği ve minör ekstremite kısalığıdır. Tedavi edilmemiş olgularda bile, iskelet matürasyonu tamamlandığında ekstremitedeki uzunluk farkı nadiren $3 \mathrm{~cm}$ 'nin üzerindedir. ${ }^{[7]}$ Çift taraflı olgularda, kalça çıkığındaki gibi ördekvari yürüyüş ve artmış lomber lordoz bulguları vardır. Büyük çocuklarda, aşırı egzersiz sonrası gluteal kaslar lokalizasyonunda nadir de olsa ağrı olabilir.

Fizik muayenede büyük trokanter daha belirgindir ve normal kalçaya göre daha proksimaldedir. Koksa vara deformitesinin artması ile birlikte abduktor kasların origo ve insersiyo bölgelerinin birbirine yaklaşması sonrası, fonksiyonel kalça abduktor kas yetmezliği ve (+) Trendelenburg testi görülür. Kalça hareketleri tüm planlarda azalmıştır, fakat en çok abduksiyon ve iç rotasyon azalmıştır. Abduksiyondaki azalma trokanter majorun pelvise çarpması nedeni ile oluşur. İç rotasyondaki azalma ise GKV olgularında sık olarak görülen femoral anteversiyonun azalmasına bağlıdır.

\section{RADYOLOJIK BULGULAR}

Pelvis ön-arka grafisinde kollodiyafizer açı azalmıştır, proksimal fiz vertikal yerleşimlidir ve genişlemiştir. Tüm olgularda görülmese de femur boynunun mediyalindeki üçgen şeklindeki kemik parçası GKV olgularına karakteristik radyolojik bulgudur. Koksa vara olgularında genellikle asetabular displazi görülür. Koksa vara deformitesi arttıkça 'acetabular slope' da artar. ${ }^{[8]}$

Proksimal femurdaki varus deformitesi boyundiyafiz açısı, femur başı-diyafiz açısı ve Weinstein ve arkadaşları ${ }^{[9]}$ tarafından tanımlanmış olan Hilgenreinerepifiz (H-E) açısı ölçülerek kantifiye edilebilir (Şekil 1). Hastalığın seyrini takipte ve rekürrens gelişimini tahminde en tutarlı ölçüm H-E açısıdır. ${ }^{[9]}$ Femur boyundiyafiz açısı ve femur başı-diyafiz açısı, $\mathrm{H}-\mathrm{E}$ açısı kadar tutarlı bir şekilde deformitenin şiddetini yansıtmaz ve prognozda kullanılmaz. ${ }^{[10]} \mathrm{H}-\mathrm{E}$ açısı Hilgenreiner çizgisi ile proksimal femur fizine paralel çizgi arasındaki açıdır ve normal değeri $0-25^{\circ}$ (ortalama $16^{\circ}$ ) arasındadır. Weinstein ve arkadaşları, 22 olguluk serilerinde $\mathrm{H}-\mathrm{E}$ açısı $60^{\circ}$ üzerinde olan olgularda deformitenin arttığını ve cerrahi tedaviye ihtiyaç duyulduğunu, $\mathrm{H}-\mathrm{E}$ açısı $45^{\circ}$ altındaki olguların ilerlemediğini ve hatta zaman içerisinde deformitenin azaldığını, $\mathrm{H}-\mathrm{E}$ açısı $45-59^{\circ}$ arasındaki olgularda prognozun belirsiz olduğunu ve bu olguların seri radyografiler ile ilerleme açısından takip edilmesi gerektiğini bildirmişlerdir. ${ }^{[11]}$ Diğer yayınlarda da H-E açısının prognozu göstermedeki önemi onaylanmıştır. ${ }^{[4,12,13]}$
GKV olguları genellikle hasta yürümeye başladıktan sonra doktora başvururlar. ${ }^{[6]}$ Klinik olarak, 

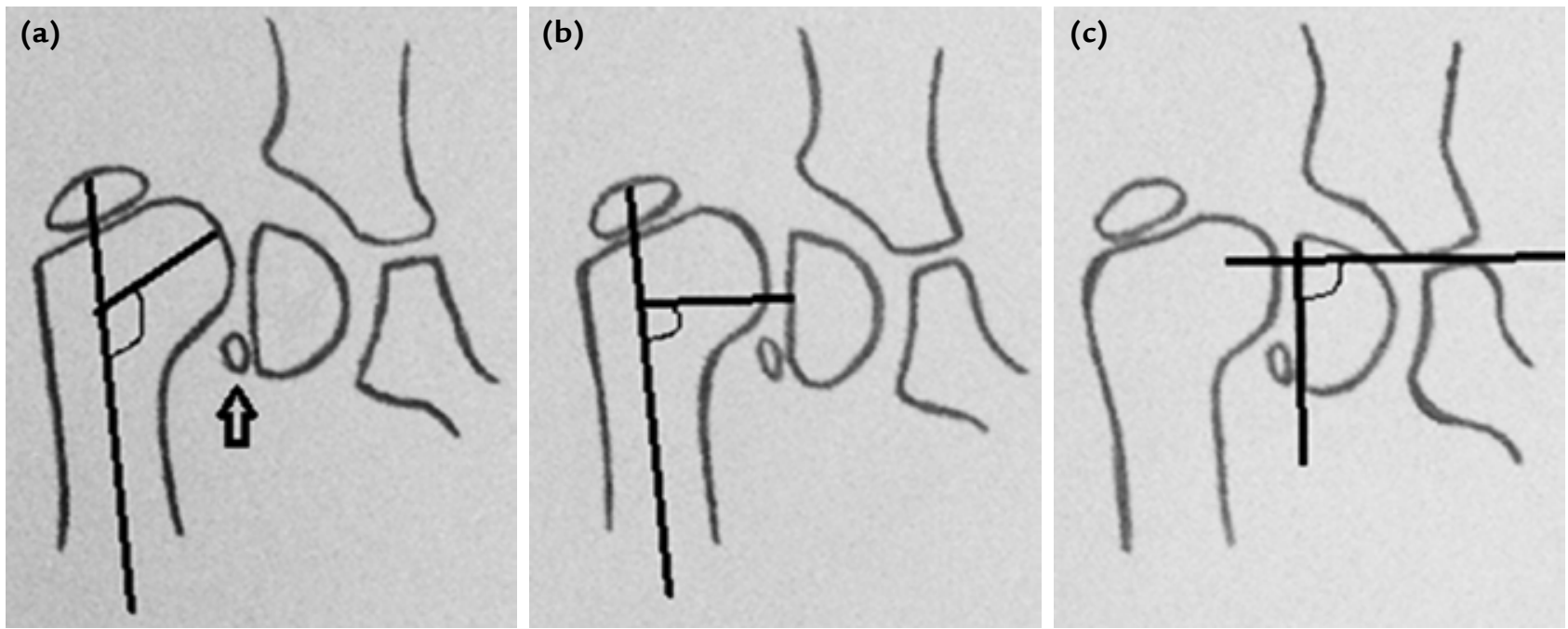

Şekil 1. a-c. Gelişimsel koksa varaya özgü triangular metafizyel parça (ok). Femur diyafiz-boyun açısı: femur diyafizine paralel ve femur boynuna paralel iki çizgi arasındaki açı (a). Femur başı-diyafiz açısı: femur diyafizine paralel çizgi ile proksimal femur fizine dik çizilen çizgi arasındaki açı (b). Hilgenreiner-epifiz açısı: Hilgenreiner çizgisi ile proksimal femur fizine paralel çizgi arasındaki açı (c).

\section{TEDAVi}

GKV tedavisindeki amaç femur boynundaki defektin iyileşmesini sağlamak, bacak boy eşitsizliğini düzeltmek, kollodiyafizer açııı normal değerlere getirmek ve kalça biyomekaniğini düzelterek kalça abduktorlarının normal fonksiyon görmesini sağlamaktır. GKV tedavisi cerrahidir; abduksiyon cihazlarının, traksiyonun ve egzersizlerin tedavide yeri yoktur. ${ }^{[1,2]}$ Semptomların süresi ve $\mathrm{H}$-E açısı ile değerlendirilen proksimal femurdaki deformite miktarı cerrahi karar almada en önemli parametrelerdir. $\mathrm{H}-\mathrm{E}$ açısı $60^{\circ}$ üzerinde olan olgularda cerrahi tedavi gerekmekte iken, $45^{\circ}$ 'nin altında olanlarda cerrahi tedavi gerekmez; $45-59^{\circ}$ arasındaki olanlarda ise takipte cerrahi gerekebilir. ${ }^{[9]}$ Bu olguların, ilerleme açısından altı ay aralıkı seri radyografiler ile takibi yapılmalıdır. Eğer bu olgularda semptomatik aksama, Trendelenburg yürüyüşü gibi bulgular gelişirse ve deformite ilerleme gösterirse cerrahi olarak tedavi yapılmalıdır. H-E açısı $45^{\circ}$ 'nin altında olan asemptomatik ve tek taraflı olgular, ekstremite uzunluk farkı açısından periyodik olarak takip edilmelidir. Bu olgularda uzunluk farkı azdır; genelde gözlem ve konservatif yöntemler ile takip edilir. Nadiren karşı ekstremitede epifizyodeze ihtiyaç duyulur.

Yıllar içerisinde GKV tedavisinde değişik cerrahi teknikler tanımlanmıştır. Bu cerrahi tekniklerden; femur boynundaki defektin greftlenmesi ve tespiti, büyük trokanterin epifizyodezi gibi altta yatan patolojiyi düzeltemeyen cerrahilerin sadece tarihsel önemi vardır. Intertrokanterik veya subtrokanterik seviyeden yapılan valgus osteotomisi, varus deformitesini düzeltmede, vertikal yerleşimli proksimal femur fizini horizontal pozisyona alarak fize gelen makaslama kuvvetlerini kompresyon güçlerine çevirmede, en etkili yöntemdir (Şekil 2, 3). 1888 yilında yapılan ilk subtrokanterik valgus osteotomisinden sonra günümüze kadar değişik eksternal ve internal tespit malzemeleri kullanılarak yapılan değişik osteotomi teknikleri tanımlanmışıtır. [1] Bunların başlıcaları, Pauwel intertrokanterik $Y$ osteotomisi[13] ve Borden tarafindan tanımlanmış olan subtrokanterik valgus osteotomisidir (Şekil 4-6). ${ }^{[14]}$ Pauwel osteotomisi teknik olarak zordur ve rotasyonel düzeltmeye izin vermez. Osteotomi ile varus düzeltilirken, femoral retroversiyon göz önünde bulundurularak, distal parça iç rotasyona alınır. Derotasyon miktarı ameliyat esnasında klinik olarak verilen bir karardır. Eğer kalçada adduksiyon kontraktürü varsa, valgus osteotomisi esnasında yapılacak adduktor tenotomi deformitenin daha kolay düzelmesini sağlar. ${ }^{[2]}$ Ayrıca, proksimal veya distal parçanın kısaltılması redüksiyonu kolaylaştırabilir. ${ }^{[2]}$ Eğer osteotomi ile yeterli bir valgus sağlanırsa, çoğu olguda ameliyat sonrası birkaç ay içinde femur boynundaki triangular metafizyel defekt spontan olarak kapanır. ${ }^{[2]}$

Bir diğer konu da cerrahi tedavinin zamanlamasıdır. Çok küçük çocuklarda tespit zorlukları yaşanırken; çocuğun büyümesini beklemek, koksa vara deformitesinin ve ikincil gelişen asetabular displazinin artmasına ve düzeltme sonrası asetabulumun remodelizasyon potansiyelinin yaş nedeniyle az olmasına 


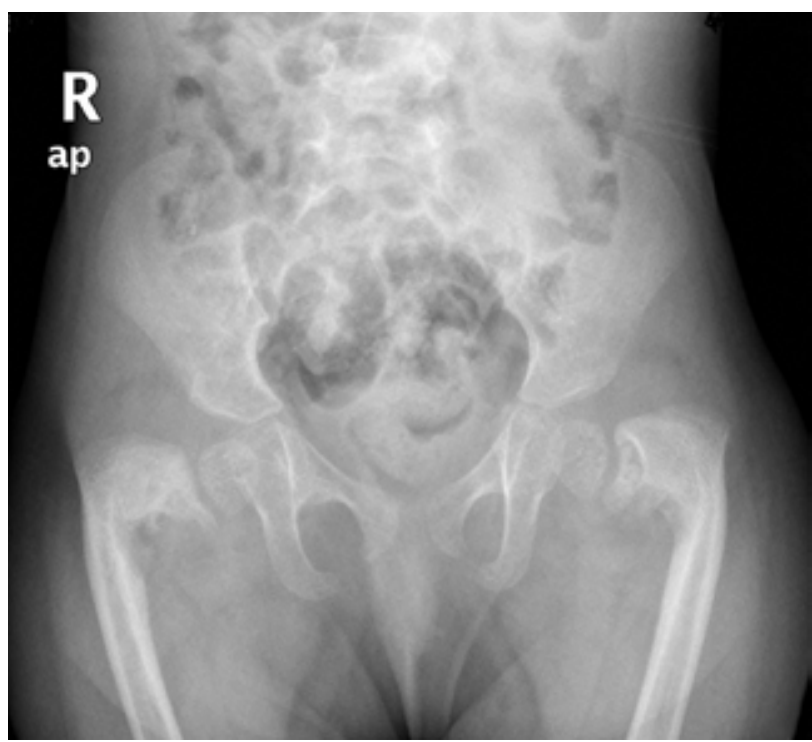

Şekil 2. Yirmi dört aylık kız hasta. Bilateral koksa vara olgusu.

neden olur. Çoğu yazar, tedaviyi yapacak cerrahın, seçeceği tespit yöntemi ile stabil bir tespit sağlayacağını düşündüğü zaman cerrahi girişimde bulunmasını önerir. Tespitte eksternal fiksatör, serklaj telleri, bifid plaklar, standart kamalı plaklar ve dinamik kalça kompresyon plakları kullanılır. ${ }^{[1,2]}$ Kamalı plak ve dinamik kalça kompresyon plakları ile yapılan tespit, en stabil tespit yöntemidir. ${ }^{[1]}$

Diğer önemli bir nokta da ne kadar valgus düzeltmesi gerektiğidir. Çünkü, zaman içerisinde olguların \%30-70'inde deformite tekrarlar. ${ }^{[4,5,9,12,13]}$ Carroll ve arkadaşları, 37 gelişimsel ve edinsel koksa vara olgusunda yaptıkları valgizasyon osteotomisi sonuçlarını geriye dönük olarak incelemişler ve sonuçta ameliyat sonrası $\mathrm{H}$-E açısını $38^{\circ}$ 'nin altına indirdikleri olguların \%95'inde rekürrens görmemişlerdir. ${ }^{[12]}$ Cordes ve arkadaşları, Pauwel osteotomisi ile tedavi ettikleri 14 olguda, $\mathrm{H}-\mathrm{E}$ açısı $40^{\circ}$ 'nin altına indirilen olgularda 11 yıllık takipte deformitenin tekrarlamadığını bildirmişlerdir. ${ }^{[13]} 2012$ yılında Abdelaziz ve arkadaşları, 27 olguda benzer sonuçlar bildirmişlerdir. ${ }^{[15]}$ Desai ve Johnson, subtrokanterik valgus osteotomisi ile tedavi ettikleri 20 kalçada $\mathrm{H}-\mathrm{E}$ açısını $35^{\circ}$ 'nin altına indirdikleri ve femur başı-diyafız açısını $130^{\circ}$ 'nin üzerine çıkardıkları olgularda 20 yıllık takipte iyi sonuç bildirmişlerdir. ${ }^{[4]} 2013$ yılında Günther ve arkadaşları, ortalama 6,2 yıl takip ettikleri ve Borden subtrokanterik osteotomisi uyguladıkları 13 hastada iyi sonuç bildirmişlerdir. Yazarlar bu osteotominin Pauwel osteotomisine göre teknik olarak daha kolay ve güvenli olduğunu; ayrıca, kama çıkarılmadığı için ekstremitede daha fazla uzama sağladığını

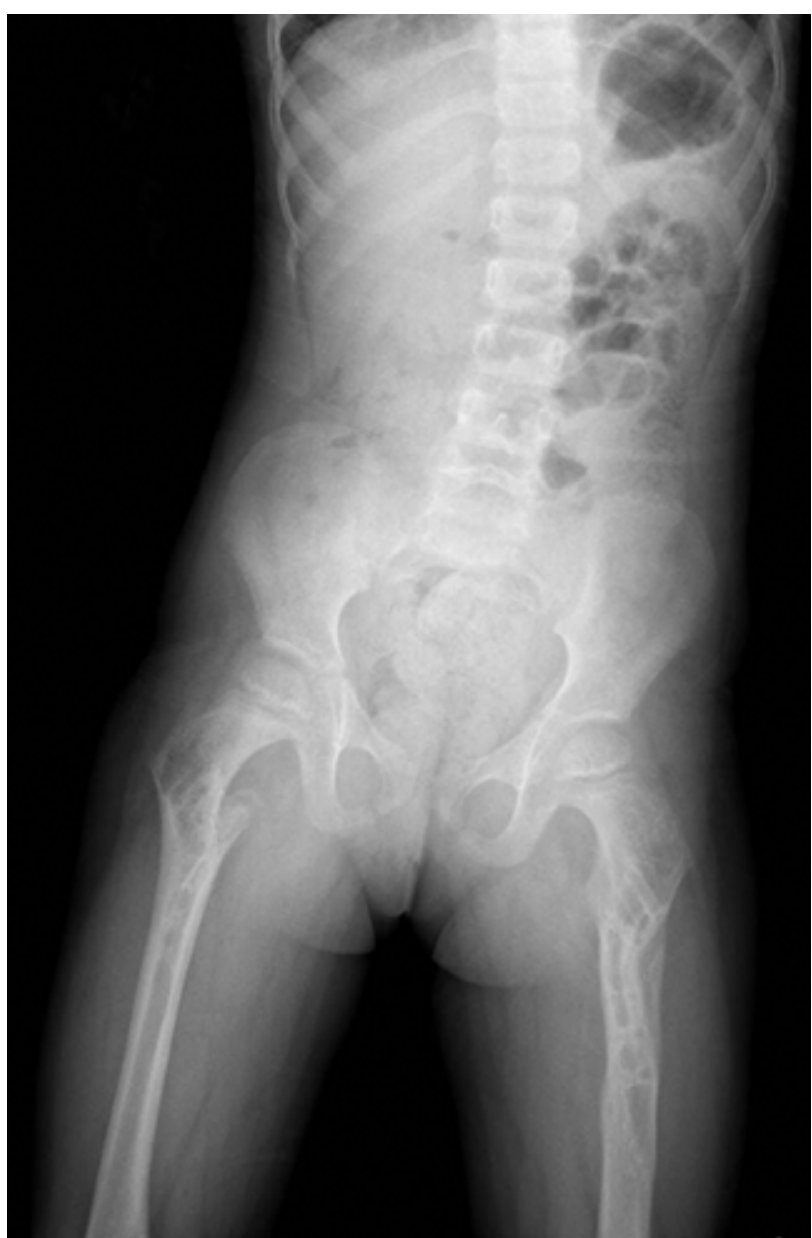

Şekil 3. Aynı hastanın ameliyat sonrası 3,5 yıl sonrası görüntüsü. Pediatrik valgizasyon plağı kullanılarak bilateral valgus osteotomisi yapıldı.

bildirmişlerdir.[16] Yine aynı yıl Hefny ve arkadaşları, eksternal fiksatör ile tespit edilen dokuz subtrokanterik valgus osteotomisi yapılmış hastanın en az iki yıllık takip sonuçlarının iyi olduğunu bildirmişlerdir. Yazarlar eksternal fiksatör kullanılarak daha iyi ve kontrollü bir düzelme sağlandığını, klasik kamalı plakla yapılan cerrahiye göre daha az kanama olduğunu, insizyonun daha az olduğunu ve plağı çıkarmak için gereken ikinci cerrahiye gerek duyulmadığını belirtmişlerdir. ${ }^{[17]}$

Özetleyecek olursak, GKV çocukluk çağının nadir görülen bir hastalığıdır. Çift taraflı olgularda altta yatabilecek olan iskelet displazisi mutlaka akılda tutulmalıdır. Tedavisinde konservatif yöntemlerin yeri yoktur. Cerrahi tedavi kararı $\mathrm{H}-\mathrm{E}$ açı değerine, semptomlara ve süresine göre alınır. Cerrahi tedavi sonrası deformitenin tekrarlamaması için $\mathrm{H}-\mathrm{E}$ açısının literatürde belirtilen değerlere indirilmesi önemlidir. 


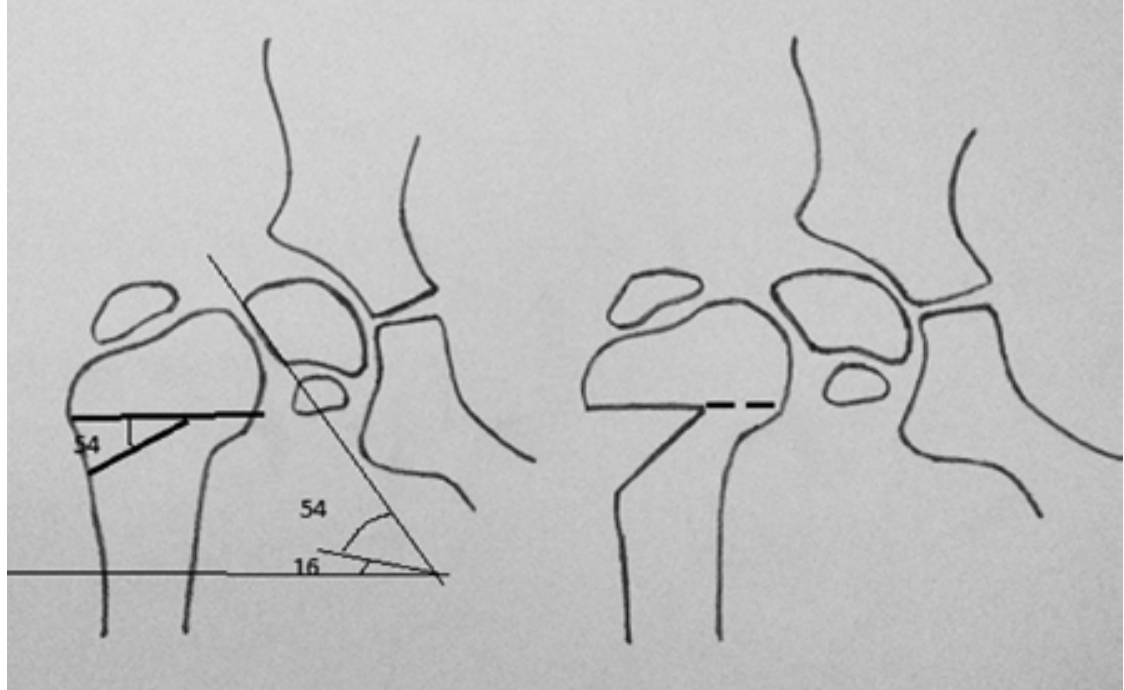

Şekil 4. Pauwel $\mathrm{Y}$ osteotomisi. $\mathrm{H}-\mathrm{E}$ açısı $70^{\circ}$ olan hastada $\mathrm{H}-\mathrm{E}$ açısını normal değeri olan $16^{\circ}$ ye indirmek için $54^{\circ}$ lateral kama çıkarılarak yapılan Y şeklindeki osteotomi.

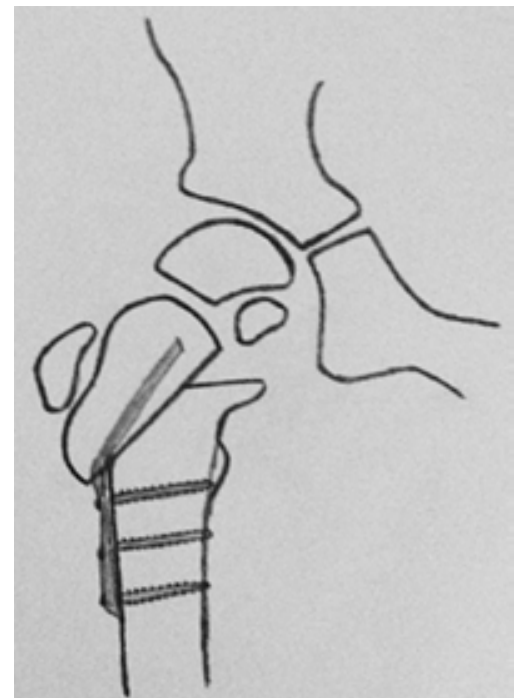

Şekil 5. Pauwel $Y$ osteotomisi yapıldıktan sonra kamalı plak ile tespit edilmiş görüntü.

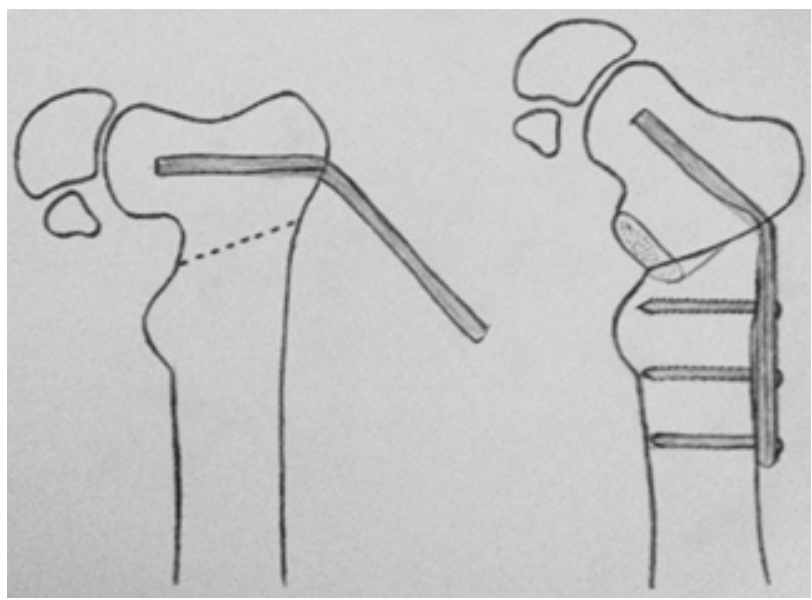

Şekil 6. Borden subtrokanterik ostetomisi. Osteotomi hattı kesik çizgi ile görülmekte. Tespit sonrası proksimal parçanın dış korteksi distal parçanın üst ucu ile temas halinde.

\section{KAYNAKLAR}

1. Herring JA. Congenital Coxa Vara. In: Herring JA, editor. Tachdjian Pediatric Orthopedics, 5th ed. Philadelphia: Elsevier; 2014. p.666-77.

2. Dobbs MB, Morcuendo JA. Other conditions of the hip. In: Lowel WW, Weinstein SL, Flynn JM, editors. Lovell and Winter's Pediatric Orthopaedics 7th ed. Philadelphia: Wolters Kluwer Health/Lippincott Williams and Wilkins; 2013. p.1222-60.

3. Johanning K. Coxa vara infantum. I. Clinical appearance and aetiological problems. Acta Orthop Scand 1951;21(4):273-99.

4. Desai SS, Johnson LO. Long-term results of valgus osteotomy for congenital coxa vara. Clin Orthop Relat Res 1993;(294):204-10.
5. Serafin J, Szulc W. Coxa vara infantum: hip growth disturbances, etiopathogenesis, and long-term results of treatment. Clin Orthop Relat Res 1991;(272):103-13.

6. Pavlov $\mathrm{H}$, Goldman $\mathrm{AB}$, Freiberger $\mathrm{RH}$. Infantile coxa vara. Radiology 1980;135(3):631-40.

7. Letts RM, Shokeir MH. Mirror-image coxa vara in identical twins. J Bone Joint Surg Am 1975;57(1):117-8.

8. Ranade A, McCarthy JJ, Davidson RS. Acetabular changes in coxa vara. Clin Orthop Relat Res 2008;466(7):1688-91. CrossRef

9. Weinstein JN, Kuo KN, Millar EA. Congenital coxa vara. A retrospective review. J Pediatr Orthop 1984;4(1):70-7.

10. Le Mesurier AB. Devolopmental coxa vara. J Bone Joint Surg $\mathrm{Br}$ 1951;33-B(3):478-82.

11. Currarino G, Birch JG, Herring JA. Developmental coxa vara associated with spondylometaphyseal dysplasia (DCV/SMD): "SMD-corner fracture type" (DCV/SMD-CF) demonstrated in most reported cases. Pediatr Radiol 2000;30(1):14-24.

12. Carroll K, Coleman S, Stevens PM. Coxa vara: surgical outcomes of valgus osteotomies. J Pediatr Orthop 1997;17(2):220-4.

13. Cordes S, Dickens DR, Cole WG. Correction of coxa vara in childhood. The use of Pauwels' Y-shaped osteotomy. J Bone Joint Surg Br 1991;73(1):3-6.

14. Borden J, Spencer GE Jr, Herndon CH. Treatment of coxa vara in children by means of a modified osteotomy. J Bone Joint Surg Am 1966;48(6):1106-10.

15. Abdelaziz TH, El-Sayed MM. Pauwels' osteotomy for surgical correction of infantile coxa vara. J Pediatr Orthop B 2012;21(4):325-30. CrossRef

16. Günther CM, Komm M, Jansson V, Heimkes B. Midterm results after subtrochanteric end-to-side valgization osteotomy in severe infantile coxa vara. J Pediatr Orthop 2013;33(4):353-60. CrossRef

17. Hefny $\mathrm{H}$, Elmoatasem EM, Nassar W. Valgus osteotomy by external fixation for treatment for developmental coxa vara. Strategies Trauma Limb Reconstr 2013;8(3):161-7. CrossRef 